\title{
Deep lab denied funding
}

\author{
Divisions within US National Science Foundation throw \\ plans for underground science facility into crisis.
}

\section{BY EUGENIE SAMUEL REICH}

A mbitious plans to build one of the world's deepest underground laboratories have suffered a serious setback. The US National Science Board (NSB) has refused to continue to fund the design of the Deep Underground Science and Engineering Laboratory (DUSEL), leaving some 1,000 researchers hoping to do science there uncertain about its future.

The lab is set to be housed in Homestake, a former goldmine near Lead, South Dakota. The mine is an ideal location for sensitive experiments trying to catch sight of hard-todetect particles such as neutrinos and dark matter. At almost 2,500 metres deep, it would shield DUSEL from the cosmic rays that would otherwise drown out signals from the lab's elusive targets.

The US National Science Foundation (NSF) and its partners, including the US Department of Energy, have already committed more than \$300 million towards DUSEL, which is expected to cost more than $\$ 800$ million in total. But Edward Seidel, assistant director for mathematical and physical sciences at the NSF, says that the \$29 million awarded to the University of California, Berkeley, in 2009 to design and prepare the mine for DUSEL has proved inadequate.

Safety concerns arose earlier this year about the mine shafts that scientists will use to access the facility. It is also proving difficult to pump groundwater from the ageing mine. As funds could not be reallocated from other parts of the project, programme managers this month requested another $\$ 19$ million now, with perhaps another $\$ 10$ million to come in the spring of 2011, to continue that preparatory work.

But the NSB, which must approve large outlays by the NSF, refused both requests on 2 December. Although the infrastructure for each of the lab's experiments will be managed by an allocated lead agency, the board was concerned by the perceived lack of a clear stewardship plan for the mine's infrastructure, raising the prospect that the NSF could face ballooning costs. Board members also believe that the energy department should contribute more than its current commitment of $\$ 100$ million.

"We don't know if this is a glitch or a death knell. I think the users feel like we're in limbo right now," says Steven Elliott, a neutron scientist at Los Alamos National

\section{$\rightarrow$ NATURE.COM} For a longer version of this story, see: go.nature.com/8p2try
Laboratory in New Mexico and chairman of the executive committee of the DUSEL Research Association, which represents the researchers who expect to do science at the new lab.

The NSB's decision also exposes internal differences at the NSF about the best way to pay for major science infrastructure projects within a funding system more attuned to supporting research programmes. Although the decision does not mean that the NSF will not build or steward the facility, says Seidel, "it's clear that the current stewardship model will have to change". The DUSEL project team is now talking to all of its partners to formulate a plan to keep preparatory work going.

Much of that work involves designing the experiments that will be lowered into caverns near the surface, and “It's clear that 1,500 and 2,300 metres the current underground. These stewardship include the Long Basemodel will line Neutrino Experihave to ment - in which change." neutrinos will be fired at detectors in DUSEL from 1,000 kilometres away at Fermilab in Batavia, Illinois, to find out why there is so much more matter than antimatter in our Universe - and LUX, the world's most sensitive search for dark matter. Beyond particle physics, DUSEL is expected to include a broad suite of geophysical and biological experiments, as well as a facility for testing the effects of sequestering carbon dioxide deep underground.

Building the lab would allow the United States to compete effectively with other countries that have underground facilities, such as the Super-Kamiokande neutrino observatory near Hida, Japan. "Here in the United States we are conspicuous in not having a deep underground science lab, in contrast to other countries with large science programmes," says Rick Gaitskell, a particle astrophysicist at Brown University in Providence, Rhode Island, who hopes to use DUSEL.

The Homestake mine currently houses the Sanford Underground Laboratory, which hosts smaller-scale versions of experiments intended for DUSEL. The additional funding is needed in part to transition the operations of this lab into the planned construction of DUSEL. The lab has enough funding to maintain the mine until May 2011, says its spokesman, Bill Harlan. A final NSF decision on whether to go ahead with DUSEL was expected in 2011, but may now be delayed. $\mathrm{a}$ 